Research Article

\title{
Experimental Research on Material and Mechanical Properties of Rock-Like Filling Materials in Disaster Prevention of Underground Engineering
}

\author{
Junwei Shi $\mathbb{D}^{1,2}$ Zhangliang Chen ${ }^{10},{ }^{1}$ and Binbin Zheng ${ }^{1}$ \\ ${ }^{1}$ School of Management Science and Engineering, Shandong Technology and Business University, Yantai 264005, China \\ ${ }^{2}$ School of Energy and Safety Engineering, Anhui University of Science and Technology, Huainan 232063, China \\ Correspondence should be addressed to Zhangliang Chen; 201513051@sdtbu.edu.cn
}

Received 30 December 2020; Revised 18 February 2021; Accepted 4 March 2021; Published 22 March 2021

Academic Editor: Xianjie Hao

Copyright (c) 2021 Junwei Shi et al. This is an open access article distributed under the Creative Commons Attribution License, which permits unrestricted use, distribution, and reproduction in any medium, provided the original work is properly cited.

\begin{abstract}
Rock-like materials can be used as a filling material to improve the stability of underground engineering substantially. And the optimization of the rock-like material is an effective way to improve the performance of the filling material. Firstly, the AHPFUZZY comprehensive optimization model was constructed for the complexity and fuzziness of the rock-like filling material ratio optimization. Secondly, according to the mechanical properties of rock-like filling materials under special environment (such as high temperature, high humidity, high stress, and high airtight) in old goaf, mechanical properties of rock-like filling materials were studied with the method of field core and laboratory test, which revealed the variation law of mechanical properties with time, and the regression equation between mechanical parameters and time was established with the method of least squares. Finally, the strength and deformation characteristics of rock-like filling materials were monitored by the monitoring and early warning technology. The results show that the optimal ratio of the rock-like filling materials is "E3"; that is, the cement content is $9 \%$, the ash ratio is $2: 5$, and the mass concentration is $74 \%$. The mass concentration is the main factor that affects the slump of the slurry, and the proportion of fly ash and coal gangue content directly affects the stratification and bleeding rate of the slurry. Reasonably increasing the ash and gangue ratio can significantly improve the workability and water retention of the rock-like filling materials. Also, the amount of composite cementitious material is the main factor that affects the setting time and the strength of the rock-like material. What is more, the special environment in gob is good for each chemical reaction fully in rocklike filling materials and strengthens the gelling property of deformation resisting capability, which can be a benefit for disaster prevention of underground engineering.
\end{abstract}

\section{Introduction}

After a decade of golden development, the coal industry has gradually entered a difficult period from 2012. On the one hand, extensive coal mining has caused destructive damage to the mine environment, such as large-scale surface subsidence, increasingly serious environmental pollution, and frequent occurrence of haze [1]. On the other hand, the development and utilization technology of various new clean energy, such as wind energy, solar energy, and nuclear energy, has led to overcapacity and difficult operation of coal mines. How to find a way of coal resources development and utilization and sustainable development of ecological environment is the focus of domestic and foreign scholars [2].

As early as the 1950s, Canada began to develop cemented filling. In China, cemented filling mining began in the mid1960s, mainly for metal ore filling. In the 1960s, filling mining began to develop in China [3]. As a key technology of green coal mining, it can effectively control the surface subsidence and improve the ecological environment of the mining area, which has been the research hotspot of domestic mining scholars [4]. Filling mining is mainly used in noncoal mines at first and has been widely used in coal mines in recent years. In the 1980s and 1990s, new technologies such as paste-like filling, rock-like filling, waste rock 
cemented filling, full-tailings cemented filling, and high water filling have been developed rapidly in coal mines [5]. The mechanical properties of rock-like filling body are the core of rock-like filling technology, and it is the key to effectively control surface deformation and prevent surface subsidence [6]. In 2003, Qian Ming, a senior academician [7], put forward a green mining technology system for underground coal mining, which laid a foundation for the development of green mining technology in China's coal mines. The optimization of the filling material ratio is an effective way to improve the performance of filling material and an important guarantee for controlling surface subsidence.

$\mathrm{Mu}$ et al. conducted orthogonal experiments on the preparation of mine filling materials with calcium carbide slag, blast furnace slag, fly ash, and flue gas desulfurization gypsum [8]. Gardner et al. studied the properties of magnesium potassium phosphate cement mixed with fly ash and ground blast furnace slag [9]. Du et al. studied the influence of fly ash characteristics on geopolymer properties [10]. Fall et al. contributed to understanding the effect of curing temperature on the mechanical properties of the colloidal end sand filling of mines [11]. Hao et al. studied the surface modification of fly ash by calcium carbide slag and its effect on the compressive strength and autoshrinkage of the blended cement paste [12]. Zhou et al. studied the diffusion behavior of respirable dust in fully mechanized coal mining face: CFD numerical simulation and engineering application [13]. Liu et al. did a study on the effects of the installation position of a multiradial swirling air-curtain generator on dust diffusion and pollution rules in a fully mechanized excavation face [14]. Zhang et al. studied and practiced the local filling technology of fly ash high water material short wall [15]. Zhang et al. studied the bearing capacity and roof stability of the filling body during the strip coal pillar paste recovery process [6]. Sobhi et al. conducted a numerical study on the earth pressure coefficient along the centerline of the backfill stope [16]. Zhang et al. studied the hydraulic characteristics of coal gangue-fly ash paste-filling and its application in underground coal mines [17].

The stability of the filling system is an important guarantee for the successful implementation of the filling mining technology and is the key to effectively controlling the surface deformation and preventing surface collapse. The filling system is a complex system, affected by multilevel and multidimensional uncertain factors. At present, scholars at home and abroad have conducted a lot of exploration and research on the stability evaluation of the filling system.

Macías et al. proposed anomalous metal-rich phosphogypsum: characterization and classification according to international regulations [18]. de Rezende et al. presented a laboratory study on phosphogypsum, stabilizers, and tropical soil mixtures [19]. Dong et al. used multiple indicators to comprehensively consider the uncertain factors of the mine to quantitatively evaluate the risk degree of underground mined-out areas and conduct case studies [20]. Wang et al. put forward a multiplane detection optimization algorithm for the design of the interval charge structure of large-diameter deep-hole blasting based on rock crushing [21]. Dong et al. indicated a quantitative evaluation and case study of multi-index clean mining considering uncertain factors for phosphate rock [22]. Sun et al. designed X-ray CT three-dimensional reconstruction and discrete element analysis of the pore structure of cement paste under uniaxial compression [23].

It can be seen that most of the domestic research on rock-like filling materials and mechanical properties is based on laboratory proportioning to prepare filling material test blocks and carry out routine mechanical property tests on them under laboratory curing conditions. Most of them have no field sampling to study the mechanical properties of the rock-like filling body in a specific underground environment (high temperature, high humidity, high stress, and high sealing), which leads to the measured data. It is not very consistent with the field measurement, and cannot reflect the actual stress and strain of the rock-like filling body. On the basis of previous research, the author explores the combination of the traditional orthogonal test method and hierarchical fuzzy mathematics method, and the combination of qualitative and quantitative methods, which not only avoids the error of human factors in the traditional filling material test but also overcomes the lack of a large amount of data in traditional mathematical statistics method. At the same time, combining with the experience and opinions of experts, the proportion of filling materials is optimized. Through field coring, the mechanical properties of the rock-like filling body and its relationship with time and the long-term stability of goaf filling body and overlying strata structure under mining disturbance are studied. It provides a reliable basis for guiding the field practice.

\section{Experimental Study on Material Properties of Rock-Like Filling Materials in Coal Mine}

2.1. Test Materials and Preparation. Coal gangue is selected as coarse aggregate, fly ash as fine aggregate, and 325 ordinary Portland cement as cementing material. The size of the test specimen is $150 \mathrm{~mm} \times 150 \mathrm{~mm} \times 150 \mathrm{~mm}$. The setting time, stratification, slump, and other parameters of the filling slurry were measured during the sample making process. After the specimen was made, the curing box was placed. The temperature was set at about $22^{\circ} \mathrm{C}$ and the humidity was adjusted to 90\%, as shown in Figures 1 and 2 . Then, core and grind the large module with test sample processing equipment (grinding machine (AHM-200); cutting machine (DQ-4)). As the standard rock sample is cylindrical with a diameter of $50 \mathrm{~mm} * 100 \mathrm{~mm}$, a $50 \mathrm{~mm}$ drill bit (inner diameter of $50 \mathrm{~mm}$ ) is used. Finally, the uniaxial compressive strength of the samples at different ages was measured by the pressure testing machine, and the experimental results were listed in the L9 $\left(3^{3}\right)$ orthogonal analysis table, as shown in Table 1. 


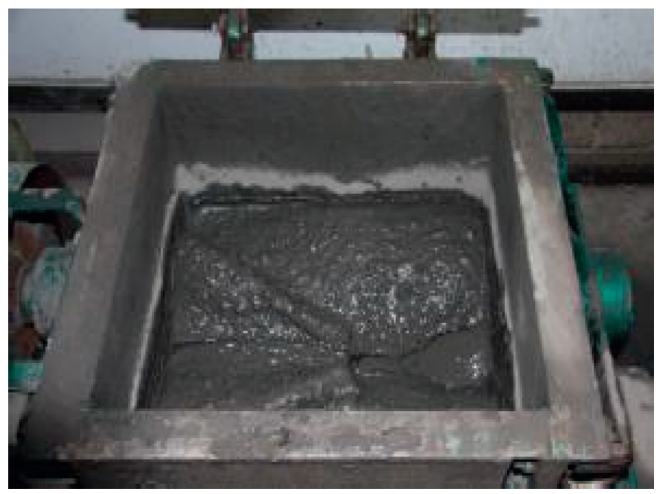

FIgURE 1: Mixing and preparation process of paste.

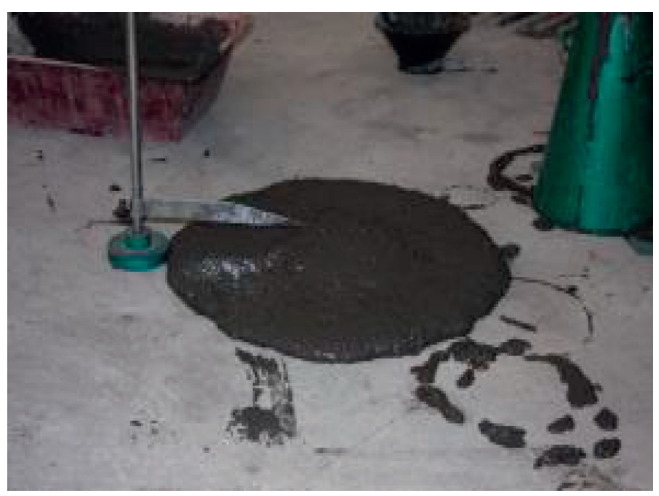

Figure 2: Slump meter test.

TABLe 1: Orthogonal test design table of filling material ratio.

\begin{tabular}{|c|c|c|c|c|c|c|c|c|}
\hline \multirow{2}{*}{$\begin{array}{l}\text { Serial } \\
\text { number }\end{array}$} & \multicolumn{3}{|c|}{ Factor } & \multicolumn{5}{|c|}{ Indicator } \\
\hline & A & B & $\mathrm{C}$ & $\begin{array}{l}\text { Slump } \\
\text { D1 }(\mathrm{cm})\end{array}$ & $\begin{array}{l}\text { Time of setting } \\
\text { D2 (h) }\end{array}$ & $\begin{array}{l}\text { Stratification } \\
\text { D3 }(\mathrm{mm})\end{array}$ & $\begin{array}{l}\text { Bleeding rate } \\
\text { D4 }(\%)\end{array}$ & $\begin{array}{c}\text { Compressive strength } \\
\text { D5 }(\mathrm{MPa})\end{array}$ \\
\hline S1 & A $(3 \%)$ & $\mathrm{a}(1: 0.5)$ & a $(74 \%)$ & 10.8 & 8.6 & 29.6 & 4.1 & 3.21 \\
\hline S2 & a $(3 \%)$ & $\mathrm{b}(1: 1)$ & b $(63 \%)$ & 16.2 & 8.1 & 5.5 & 1.5 & 1.01 \\
\hline S3 & a $(3 \%)$ & $c(2: 5)$ & c $(68 \%)$ & 6.8 & 7.3 & 2.1 & 0.87 & 1.05 \\
\hline S4 & B (9\%) & $\mathrm{a}(1: 0.5)$ & c $(68 \%)$ & 18.5 & 7.2 & 33.2 & 3.4 & 2.56 \\
\hline S5 & B $(9 \%)$ & $\mathrm{b}(1: 1)$ & $1(74 \%)$ & 11.3 & 5.6 & 4.7 & 2.31 & 4.22 \\
\hline S6 & B $(9 \%)$ & $c(2: 5)$ & b $(63 \%)$ & 22.6 & 7.1 & 11.8 & 3.5 & 2.87 \\
\hline S7 & C (16\%) & $\mathrm{a}(1: 0.5)$ & b $(63 \%)$ & 16.5 & 5.8 & 16.9 & 3.2 & 1.86 \\
\hline S8 & c $(16 \%)$ & $\mathrm{b}(1: 1)$ & c $(68 \%)$ & 23.4 & 5.4 & 13.9 & 1.58 & 3.45 \\
\hline S9 & c $(16 \%)$ & $c(2: 5)$ & $\mathrm{a}(74 \%)$ & 18.7 & 6.58 & 3.53 & 3.02 & 3.97 \\
\hline
\end{tabular}

2.2. Experimental Scheme Design. Three factors and three levels of orthogonal table were used to design the orthogonal experiment scheme. Three factors are selected in this filling material ratio test: cement quality/mixture quality is recorded as cement content a; fly ash mass/coal gangue mass is recorded as ash gangue ratio $\mathrm{B}$; and slurry mass concentration $C$. Three levels of factor a cement content are selected, which are $\mathrm{A}(\mathrm{a}): 3 \%, \mathrm{~A}(\mathrm{a}): 9 \%, \mathrm{~A}(\mathrm{c}): 16 \%$; factor $\mathrm{B}$ : ash gangue ratio: $\mathrm{B}(\mathrm{a}): 5: 2, \mathrm{~B}(\mathrm{~b}): 1: 1, \mathrm{~B}(\mathrm{c}): 2: 5$; and factor C: slurry mass concentration, C (a): 74\%, C (b): $63 \%, C$ (c): $68 \%$; the test scheme is designed according to the design principle of rock-like filling materials of Jinchuan company.
The relevant indexes meeting the requirements of pumpability, fluidity, and mechanical properties of filling paste were selected, including slump D1, setting time D2, stratification D3, bleeding rate $\mathrm{D} 4$, and compressive strength $(28 \mathrm{~d})$ D5. Through range analysis and visual analysis, the average of each test factor was compared, and the corresponding indexes D1, D2, D3, D4, and D5 were obtained. The optimal proportion combination of rock-like filling materials was A (b), B (a), and C (b); A (c), B (b), and C (c); A (c), B (c), and C (c); A (c), B (c), and C (c); A (c), B (c), and C (1). Therefore, according to each index D1 D5, the L9 (33) orthogonal test scheme of nine groups of rock-like filling 
materials in Table 1 was optimized, and finally five groups of optimal proportion combinations were determined, which were, respectively, recorded as schemes E1, E2, E3, E4, and E5. It can be seen that, corresponding to indexes D3 and D4, the optimal mix proportion combination of rock-like filling materials, namely, E3 and E4 test schemes, are all A (c), B (c), and $C(a)$. Since the range values of factors $A(b)$ and $A(c)$ corresponding to index D3 are basically the same, so the optimal ratio combinations of E3 are A (b), B (c), and C (a), as shown in Table 2.

\subsection{Construction of Optimization Index System of Filling} Material Ratio. According to the practice of mine filling and the previous research in literature [22-24], the main factors affecting the optimization of filling material ratio can be divided into internal and external factors. The internal factors include the pumpability and fluidity of the filling material and the strength and mechanical stability of the filling body. The external factors include the stability of the filling system and the economy of filling materials. Therefore, based on APH theory, a three-level optimization index system of filling material ratio is constructed, which takes the optimization of filling material ratio as the target layer, four factors as the criterion layer, four factors as the criterion layer, and seventeen factors as the index layer, such as the strength of filling body and the compactness of filling body, to form a three-level optimization index system of filling material proportion, as shown in Figure 3.

Stability of filling body: the stability of the filling body is directly related to the filling quality, that is, whether the filling body can effectively support the overlying strata and control the surface subsidence. The strength of the filling body includes initial strength, namely, self-supporting strength and long-term strength [25]. It is found that the content of cementitious material is the main factor affecting the strength of filling slurry, and the strength of filling slurry can be effectively improved by increasing the content of cementitious material. The compactness and cementation of the backfill are also the main factors affecting the stability [26]. The better the compactness and cementation are, the less likely the backfill is to be compressed and more stable. In addition, the top connection rate of the filling body will also affect the stability of the filling body [27]. The higher the top connection rate is, the earlier the deformation and movement of surrounding rock can be limited, and the support system of roof filling body floor can be formed, so as to improve its own stability, effectively control the movement and deformation of surrounding rock, and reduce the surface subsidence.

Pumpability of filling materials: the pumpability of filling materials is the main index to measure the performance of filling materials. It refers to that the filling materials are pumped into the goaf for filling through filling pumps, filling pipelines, and sometimes expressed by mobility. The pumpability or fluidity of filling materials will directly affect the performance of filling materials and even cause the plugging of filling pipelines and paralyze the whole filling system. The flow properties of filling materials are directly affected by filling mass concentration, setting time, stratification, workability, and bleeding. It is found that [28-31], the mass concentration is the main factor affecting the workability of filling materials, and the specific gravity of fly ash and coal gangue directly affects the layering degree and bleeding rate of filling materials. The amount of cement is the main factor affecting the setting time and strength of the filling material. Therefore, the pumpability of filling materials can be improved by adjusting the mass concentration of filling materials and the content of fly ash.

Stability of filling system: the complete filling system consists of five parts: the supply system of filling raw materials, the preparation system of filling slurry, the filling pumping system, the filling pipeline system, and the filling stope system. The proportion and performance of filling materials are related to the composition and stability of the filling system and then affect the filling efficiency [32]. The stability of the filling system mainly includes the working environment of stope, stability of filling pipeline, stability of filling equipment and facilities, occupational health, and hygiene of personnel.

Economy of filling materials: the economy of filling materials is an important condition for optimizing the proportion of filling materials and an important part of filling mining costs, including the transportation economy of filling materials, the economy of cementing materials and aggregates, the economy of supporting filling systems, and the recycling of filling materials [33].

\subsection{Determination of Index Weight for Optimization of Filling} Material Ratio. Based on the analysis of the factors influencing the optimization of the filling material ratio, the relative importance of the stability of the filling body $\mathrm{C} 1$, the pumpability of the filling material $\mathrm{C} 2$, the stability of the filling system $\mathrm{C} 3$, and the economic efficiency of the filling material C4 are analyzed by the general 1-9 scaling method [34], and the judgment matrix is obtained through the investigation and analysis of the actual situation of the site. Finally, the expert's opinions were obtained. The specific steps are as follows .

(1) The general 1-9 scale method is used to determine the judgment matrix $A$, as shown in Table 3 .

(2) The weight vector of influencing factors of the stability of the filling body, the pumpability of the filling material, the economy of the filling material, and the stability of the filling system on the optimization of the filling material proportion of the target layer are obtained by the summation method (approximate method). The column vectors of the judgment matrix are normalized, then the row vector is summed to get the weight matrix, and after that the column vector is normalized. The result is the criterion layer weight of each factor.

(3) Calculate the maximum eigenvalue of judgment matrix $\lambda_{\max }:$ it is solved by $A W=\lambda W$.

(4) The maximum eigenvalue is obtained as follows: 
TABLE 2: Optimization scheme of filling material ratio.

\begin{tabular}{lccc}
\hline Test scheme & Indicator & Optimal combination of factor levels & Description of preferred ratio combination \\
\hline E1 & D1 & A (a), B (A), C (b) & Cement content 9\%, ash gangue ratio 5:2, mass concentration 63\% \\
E2 & D2 & A (c), B (b), C (a) & Cement content 16\%, ash gangue ratio 1:1, mass concentration 74\% \\
E3 & D3 & A (b), B (c), C (a) & Cement content 9\%, ash gangue ratio 2:5, mass concentration 74\% \\
E4 & D4 & A (c), B (c), C (c) & Cement content 16\%, ash gangue ratio 2:5, mass concentration 68\% \\
E5 & D5 & A (c), B (c), C (a) & Cement content 16\%, ash gangue ratio 2:5, mass concentration 74\% \\
\hline
\end{tabular}

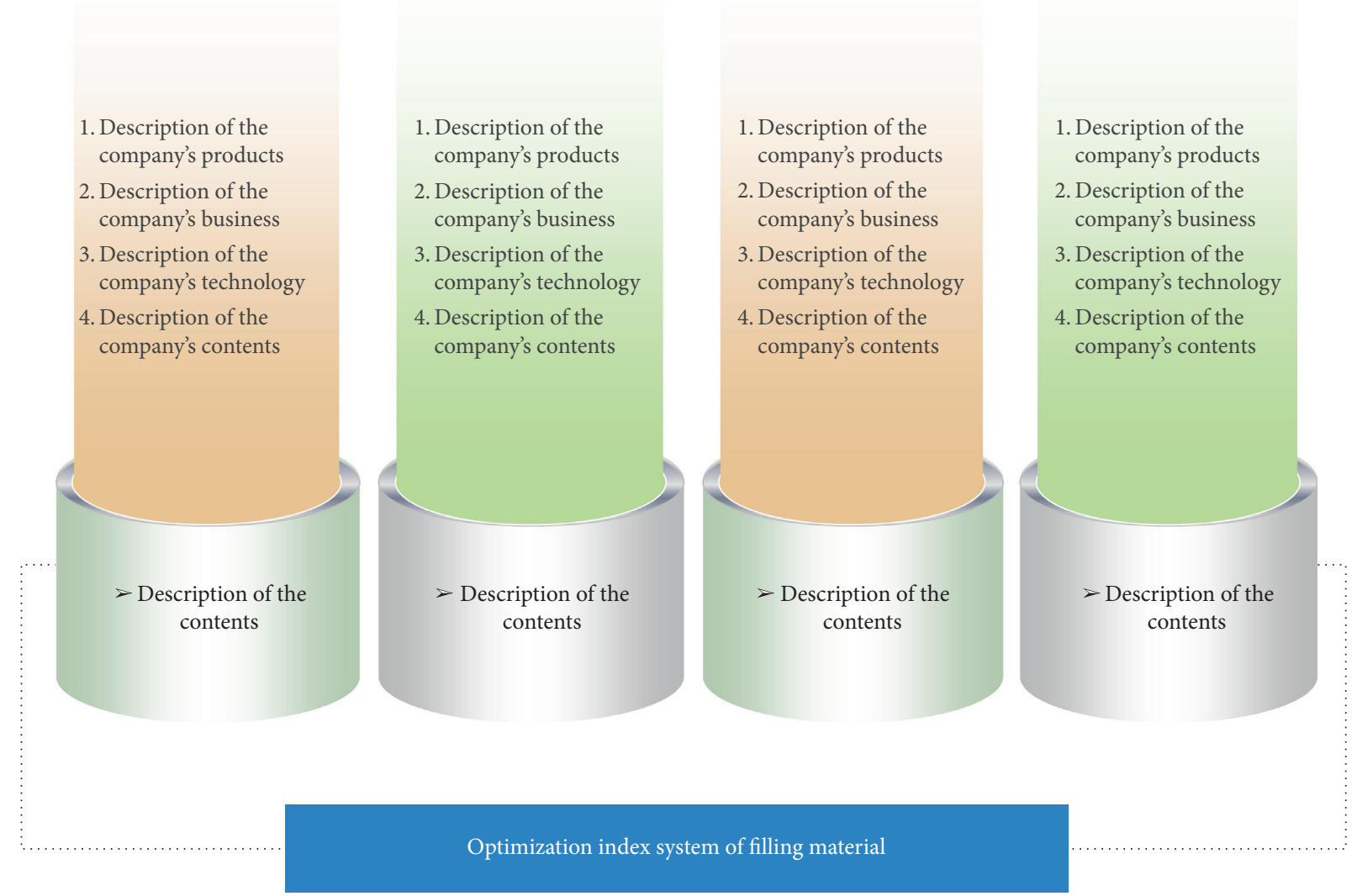

FIgURE 3: Optimization index system of filling material.

TABle 3: The judgment matrix $A$.

\begin{tabular}{lccccc}
\hline$A$ & $U 1$ & $U 2$ & $U 3$ & $U 4$ & Weight \\
\hline$U 1$ & 1 & 2 & 6 & 4 & 0.5128 \\
$U 2$ & $1 / 2$ & 1 & 4 & $1 / 2$ & 0.2755 \\
$U 3$ & $1 / 6$ & $1 / 4$ & 1 & 0.0740 \\
$U 4$ & $1 / 4$ & $1 / 2$ & $\mathrm{CR}=0.0039<0.10$ & 0.1377 \\
$\lambda_{\max }=4.0104$ & & & \\
\hline
\end{tabular}

$$
\lambda \max =\frac{1}{n} \sum_{i=1}^{n} \frac{(A W)_{i}}{\omega i}
$$

(5) The consistency index is obtained as follows:

$$
C \cdot I=\frac{\lambda \max -n}{n-1} .
$$

(6) Since the judgment matrix is a fourth-order matrix, the random consistency index table [35] shows that

$$
R \cdot I=0.89 \text {. }
$$

(7) Consistency ratio:

$$
C \cdot R=\frac{C \cdot I}{R \cdot I}=0.0039<0.1 .
$$


It is obvious that the consistency is satisfied.

The weight vector of other index layers can be obtained by the same method, as shown in Table 1 .

\subsection{Fuzzy Comprehensive Optimization of Filling Material Ratio}

2.5.1. The Optimization Factor Set and Weight Set of Filling Material Ratio Were Established. According to the index system Figure 3 of rock-like filling material ratio optimization, the influence factors of filling material proportion optimization are divided into various factors, and the factor sets are established, respectively. The factor set of criterion layer includes the stability of the filling body, the pumpability of filling material, the stability of the filling system, and the economy of filling material.

2.5.2. Construction of Fuzzy Evaluation Matrix. By using the Delphi method, the relevant persons in charge of filling mining in coal mining enterprises, construction directors of labor engineering companies, and relevant experts from universities and industries are invited to evaluate the index system for the optimization of filling material proportioning, combining with the practice of mine filling mining, and the influence of each criterion layer and index layer factor on the optimization of filling material ratio under different test schemes $(\mathrm{E} 1 \sim \mathrm{E} 5)$ is obtained at the sound level, as shown in Table 4.

For example, R1: for the index filling body strength, 4 out of 40 people think that the strength of filling body in scheme E1 has a great influence on the optimization of filling material proportion, and 2 people think that the strength of filling body in scheme E2 has a great influence on the optimization of filling material proportion (the same as others), as shown in Figures 4(a)-4(d).

2.5.3. First-Order Fuzzy Comprehensive Optimization. Operator $M(\times, \oplus)$ is used to make a fuzzy comprehensive evaluation on the optimization scheme of coal mine filling material proportion, and the evaluation result of filling body stability factor index is $A 1$. In the same way, the evaluation result vector of other factors affecting the optimization of coal mine filling material ratio can be obtained as $B$ :

$$
\begin{aligned}
& B=A R=\left[\begin{array}{llll}
0.51 & 0.28 & 0.07 & 0.14
\end{array}\right]\left[\begin{array}{ccccc}
0.04 & 0.25 & 0.32 & 0.32 & 0.07 \\
0.12 & 0.44 & 0.30 & 0.12 & 0.02 \\
0.11 & 0.49 & 0.25 & 0.11 & 0.04 \\
0.07 & 0.38 & 0.36 & 0.12 & 0.07
\end{array}\right] \\
& =\left[\begin{array}{lllll}
0.0715 & 0.3151 & 0.3382 & 0.2213 & 0.0539
\end{array}\right] \text {. }
\end{aligned}
$$

Therefore, according to the principle of maximum membership degree, the fuzzy comprehensive optimization scheme of gangue gypsum filling material proportion is ranked as follows: E3 $>$ E2 $>$ E4 $>$ E5 $>$ E1. The optimal proportioning scheme is "E3." They are A (b), B (c), and C (a). The cement content is $9 \%$, the ratio of ash to gangue is 2 : 5 , and the mass concentration is $74 \%$. It can be seen that the sensitivity of "ash to gangue ratio" is the highest in the process of filling material proportion optimization, followed by "cement content" and "mass concentration," and the two are basically the same sensitivity to the optimization of filling material proportion. Therefore, the proportion of fly ash and gangue, that is, the proportion of fly ash and coal gangue, should be paid more attention to in the optimization of filling material proportion. The test results show that a proper amount of fly ash has a positive effect on improving the pumpability of filling material, but excessive fly ash will affect the performance of filling material.

\section{Experimental Study on Mechanical Properties of Rock-Like Filling Materials in Coal Mine}

3.1. Site Coring Scheme. In order to study the mechanical properties of backfill behind the wall, the paste samples were drilled at 2301 working face in Daizhuang coal mine of Zibo Mining Group. The filling body with filling time $t \leq 30 \mathrm{~d}$ is selected as the research object. According to the filling technology of 2301 working face in Daizhuang coal mine, a cycle of three days is conducted, and the drilling depth should be $40 \mathrm{~m}$. The drilling depth of No. 3 hole in this sampling is $50 \mathrm{~m}$, which is located in the middle of the working face; the drilling depth of No. 4 hole is $42 \mathrm{~m}$, which is $20 \mathrm{~m}$ away from the track trough of 2301 working face, and the distance between No. 3 hole and No. 3 hole is $27 \mathrm{~m}$. The positions of hole 3 and hole 4 on the 2301 working face are shown in Figure 5. 
TABLE 4: Judgment matrix of filling stability.

\begin{tabular}{lcccccc}
\hline \multirow{2}{*}{ Factor } & \multicolumn{3}{c}{ Evaluation matrix } & & E5 & Index weight $W_{1}$ \\
& E1 & E2 & E3 & E4 & 0.15 & 0.5128 \\
Strength of filling body $P_{11}$ & 0.15 & 0.06 & 0.24 & 0.8 & 0.28 & 0.2755 \\
Compactness of filling body $P_{12}$ & 0 & 0 & 0.6 & 0.5 & 0.040 & 0.0740 \\
Cementation of filling body $P_{13}$ & 0.04 & 0.08 & 0.6 & 0.38 & 0.08 & 0.1377 \\
Top connection rate of filling body $P_{14}$ & 0.46 & 0.06 & 0.28 & 0.25 & & \\
\hline
\end{tabular}

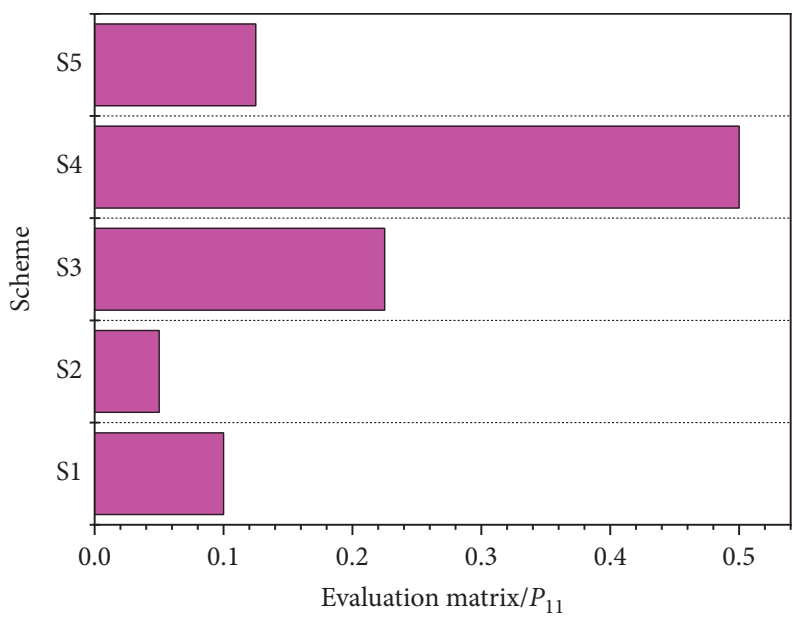

(a)

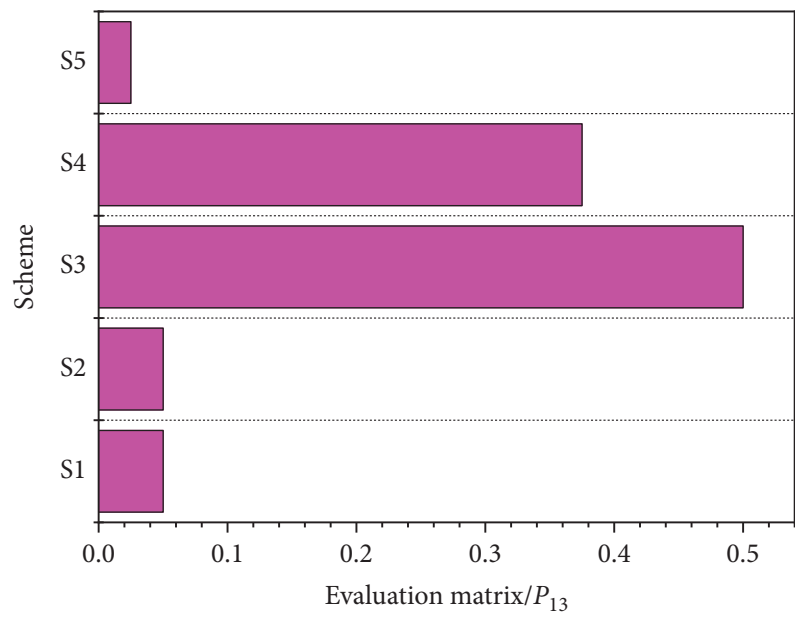

(c)

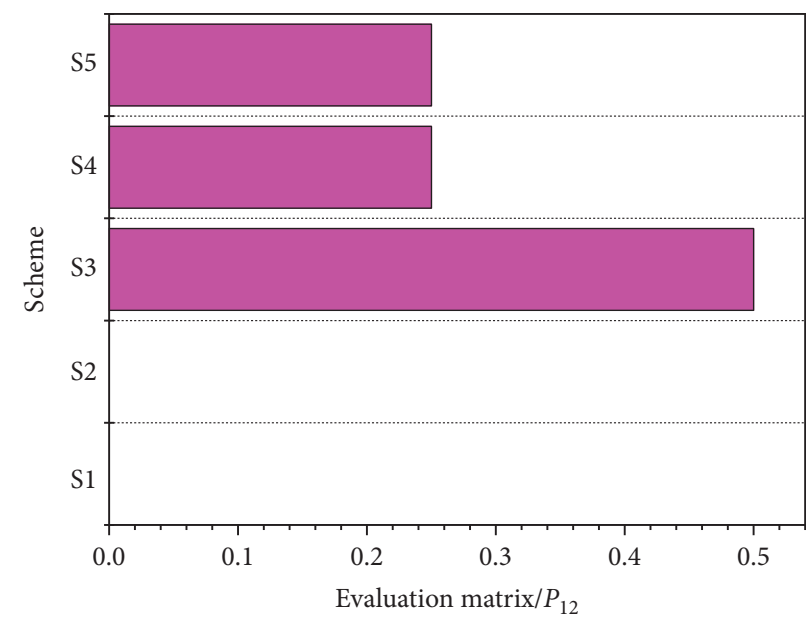

(b)

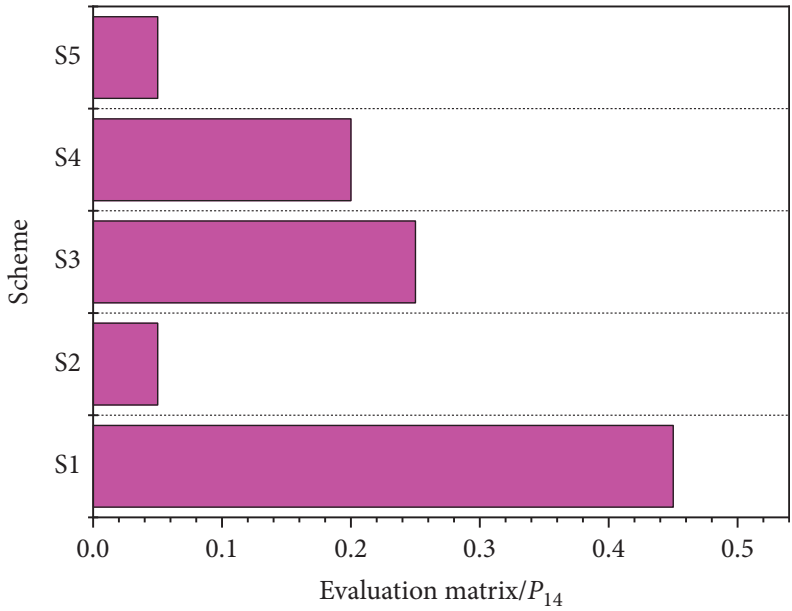

(d)

FIGURE 4: Evaluation matrix of various factors.

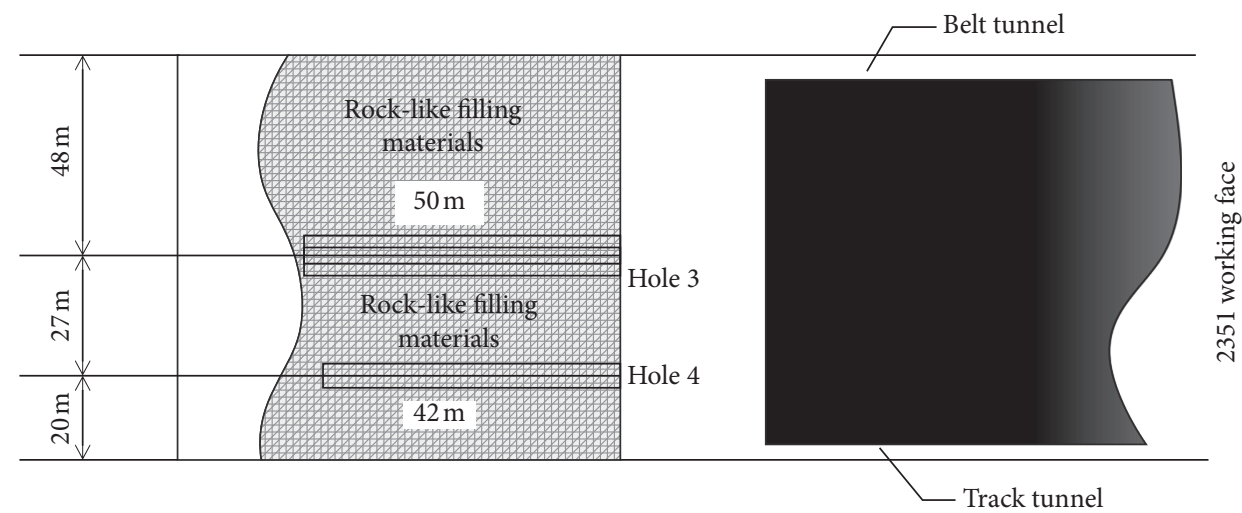

FIgURE 5: Arrangement scheme of drill hole sampling. 
3.2. Preparation of Standard Specimen. This time, a $50 \mathrm{~mm}$ drill bit was used for coring, which was sealed after coring on-site, so as to prevent weathering and keep the original as much as possible. The drilling depth is $4 \mathrm{~m}, 8 \mathrm{~m}, 12 \mathrm{~m}, \ldots$, $44 \mathrm{~m}$ (i.e., the age is $1 \mathrm{~d}, 4 \mathrm{~d}, 7 \mathrm{~d}, \ldots, 31 \mathrm{~d}$ ); the cores were processed again in the laboratory. The processed specimen is a neat cylinder, the ratio of height to diameter is $2.5-3.0$, the diameter is about $50 \mathrm{~mm}$, the end face of the specimen is flat to $0.02 \mathrm{~mm}$, and the perpendicularity of the specimen axis is not more than $0.05 \mathrm{~mm}$, which can meet the standard of rock test specification. According to the different ages $(1 \mathrm{~d}, 4 \mathrm{~d}$, $7 \mathrm{~d}, \ldots, 31 \mathrm{~d}$ ) of the specimens made from hole 3 and hole 4 , respectively, they were divided into 11 groups and numbered as $A_{i}$ (hole 3 ) and $B_{i}$ (hole 4), $i=1,211$ [36]. Six standard specimens were selected for each group, numbered $A_{i}{ }_{j}$ (hole 3 ) and $B_{i}-{ }_{j}$ (hole 4 ), $i=1,211, j=1,2, \ldots, 6$. Finally, three standard specimens were selected from each group for uniaxial tensile test, and the other three specimens for uniaxial compression test. The average value of each group was taken as the test results. In order to reduce the influence of drilling position on the mechanical property test of rocklike filling body and reduce the experimental error as much as possible, the average value of the results obtained from the samples of No. 3 hole and No. 4 hole in the same group is taken. Some standard samples obtained in this test are shown in Figure 6.

\subsection{Mechanical Properties Analysis of Rock-Like Filling Body}

3.3.1. Relationship between Tensile Strength and Time of Backfill. By using the least square method, the regression curves 1 and 2 of the tensile strength of the filling body with time are obtained, as shown in Figure 7.

It can be seen from Figure 7 that the tensile strength of the filling body increases with time. The change of tensile strength of the filling body with time can be divided into three stages: the first stage $(1 \sim 18 \mathrm{~d})$ is a rapid growth period, the tensile strength of filling body increases rapidly with time, and the increase range is $86 \%$, the compressive strength of filling body reaches $89.8 \%$ of the final strength after $18 \mathrm{~d}$; the second stage (18 30 d), which is a slow growth period, increases slowly with time; the third stage ( $\geq 30 \mathrm{~d}$ ) is a stable period. With the increase of time, the compressive strength of backfill almost does not increase, reaching the ultimate tensile strength of $1.198 \mathrm{MPa}$.

\subsubsection{Relationship between Uniaxial Compressive Strength} and Time of Backfill. By using the least square method, the regression curves of the uniaxial compressive strength of the filling body with time are obtained, as shown in Figure 8. It can be seen from the figure that, overall, with the increase of time, the uniaxial compressive strength of the filling body gradually increases, the increase range decreases from large to small, and finally tends to be stable, and the compressive strength of the filling body is almost unchanged. Locally, with the increase of time, the uniaxial compressive strength of the filling body is almost unchanged. The uniaxial compressive strength of the backfill specimens showed a leap forward increase. There are two peaks in the process of "leap forward." The first peak appears at the age of 6 days, which is 3.06 times the compressive strength of $1 \mathrm{D}$ filling body. The second peak appears at the age of 18 days, which is 4.25 times of the compressive strength of $1 \mathrm{D}$ filling body. It shows that when the age is 18 days, the chemical reaction of various compounds in the filling body is the strongest, forming C-S-H gel and $\mathrm{Ca}(\mathrm{OH}) 2, \mathrm{C} 3 \mathrm{AH} 6, \mathrm{AFt}$, and other products. These products have strong gelling properties and in a certain way rely on a variety of gravitational links to form a cement stone structure to produce greater strength. The uniaxial compressive strength of the filling body tends to be stable after 21 days, and the compressive strength of the filling body is basically stable at $6.0 \mathrm{MPa}$. This is because the internal chemical action and mechanical properties of the filling body tend to be stable, and the effect of various factors on the strength of the filling body will also tend to be stable.

It can be seen from Figure 9 that the uniaxial compressive strength of the $28 \mathrm{~d}$ test piece is $4.7 \mathrm{MPa}$ under the optimal proportioning conditions of coal gangue gypsum filling material and laboratory curing conditions (curing temperature is $21 \pm 1^{\circ} \mathrm{C}$, humidity is $83 \%$ ), and the compressive strength of filling body after 21 days measured by field coring is $6.0 \mathrm{MPa}$, which is 1.3 times of the former. This shows that the specific environmental conditions in coal mine, namely, high temperature and humidity and confined space (the actual measured internal temperature of filling paste is about $50^{\circ} \mathrm{C}$ ), are conducive to the full reaction of various chemical substances in the filling body, so that the cementitious property of the filling body is enhanced, so that it is stable and has high strength before 28 days.

\section{Field Monitoring of Long-Term Stability of Rock-Like Filling Materials}

The online monitoring system for the long-term stability of the rock-like filling body in the coal mine is mainly composed of monitoring server, communication interface, underground monitoring master station, multifunctional monitoring substation, mine data optical terminal, and supporting explosion-proof system. The well monitoring server uses an industrial PC to extend RDS or optical fiber interface. Office LAN users access the well monitoring server through telephone line, optical fiber, or/and Ethernet ring network, and the monitoring information of the well monitoring server is shared by client mode or IE mode. The underground monitoring master station is responsible for patrolling each underground monitoring substation, and the patrolling data is transmitted to the underground monitoring server. The system adopts a multilevel bus distributed structure and intrinsically safe design. The maximum monitoring capacity of the system can reach 1000 measuring points. The monitoring server can access the mine LAN through OPC or FTP. The monitoring server software adopts $C / S+B / S$ structure. The users of office LAN can share monitoring information through client mode or IE mode. The underground monitoring master station has built-in 


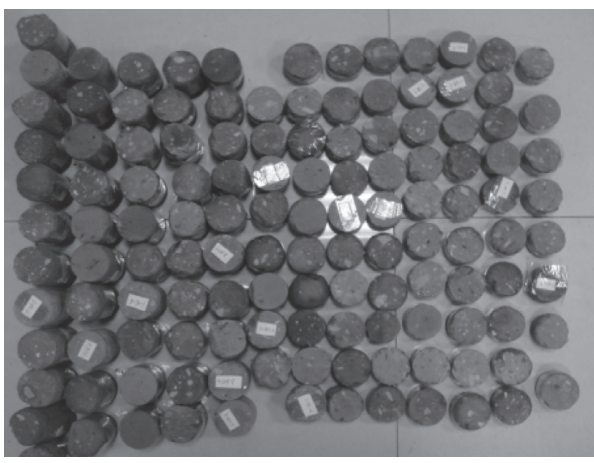

(a)

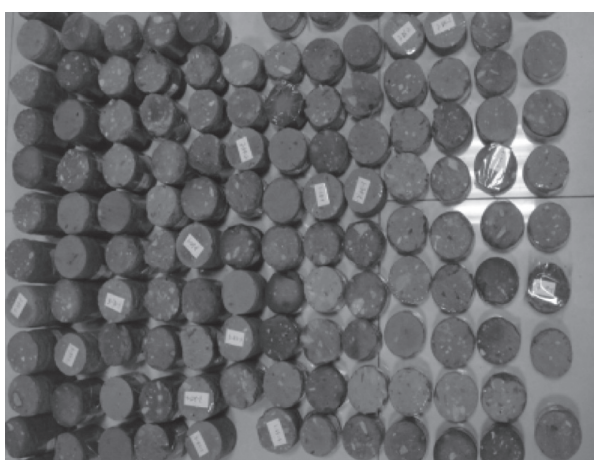

(b)

Figure 6: Part of standard samples for this test. (a) Standard sample of No. 3 hole. (b) Standard sample of No. 4 hole.

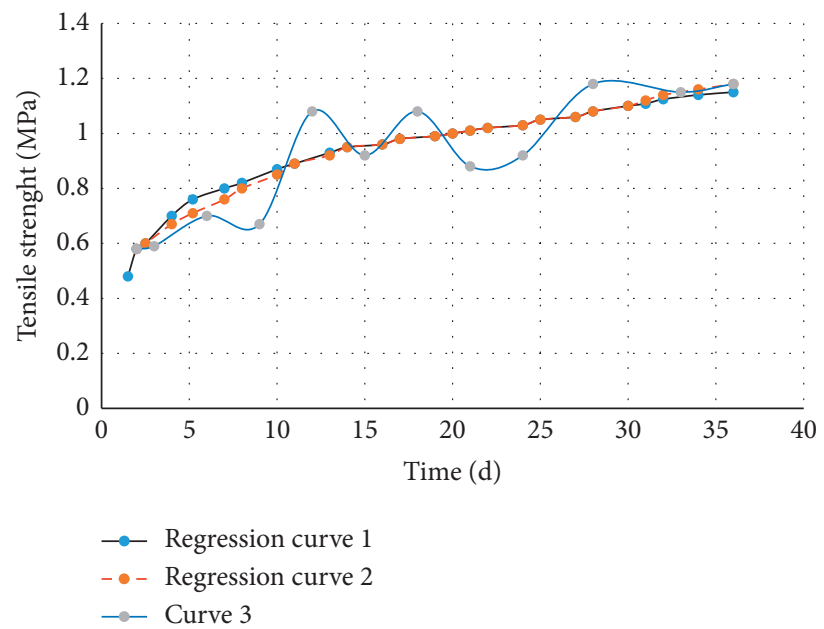

Figure 7: Curves of paste-filling tensile strength changing with time.

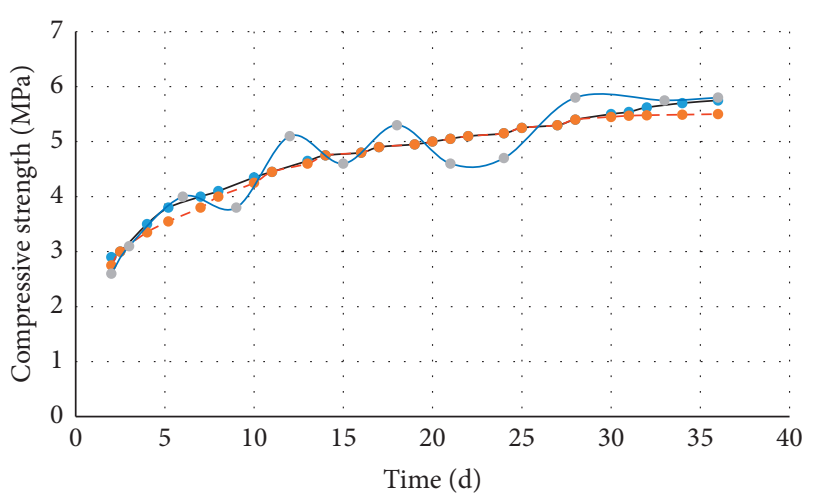

- - Regression curve 1

- - Regression curve 2

- - Curve 3

FIGURE 8: Curves of paste-filling uniaxial compression strength changing with time.

RDS and NPORT interfaces. Users can choose a telephone line, optical fiber, and ring network to connect with the underground monitoring server. The underground monitoring substation has the functions of data display, bus communication, and alarm. The substation is connected with the substation through the RS485 bus. The monitoring system is shown in Figure 10.

4.1. Subsidence Monitoring System of Filling Body Top and Bottom Plate. The special KBU101-200 roof subsidence position state instrument is used to measure the roof and floor subsidence of goaf. The measuring range is extended to $500 \mathrm{~mm}$. The gear rack structure is used to convert the linear displacement into angular displacement. The displacement signal is converted into a voltage signal through the internal angular displacement sensor. The digital signal is collected by a single chip microcomputer. The monitor has a built-in 485 communication interface to transmit the data to RS48 5 bus.

KBU101 roof subsidence position instrument adopts elastic energy storage piston rod displacement structure, which can make the sensor waterproof and sealed, and the position instrument has zero calibration function. The length of the instrument itself is $1.7 \mathrm{~m}$, and the measuring range of the extension rod can be up to $3.0 \mathrm{~m}$. If the height to 


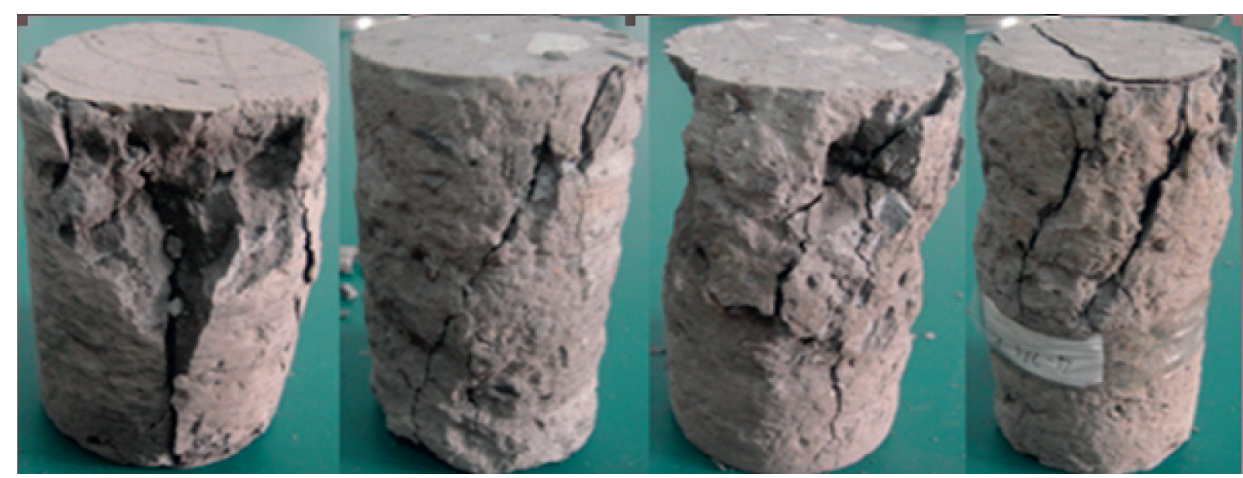

Figure 9: Photograph of broken filling paste after uniaxial compression test.

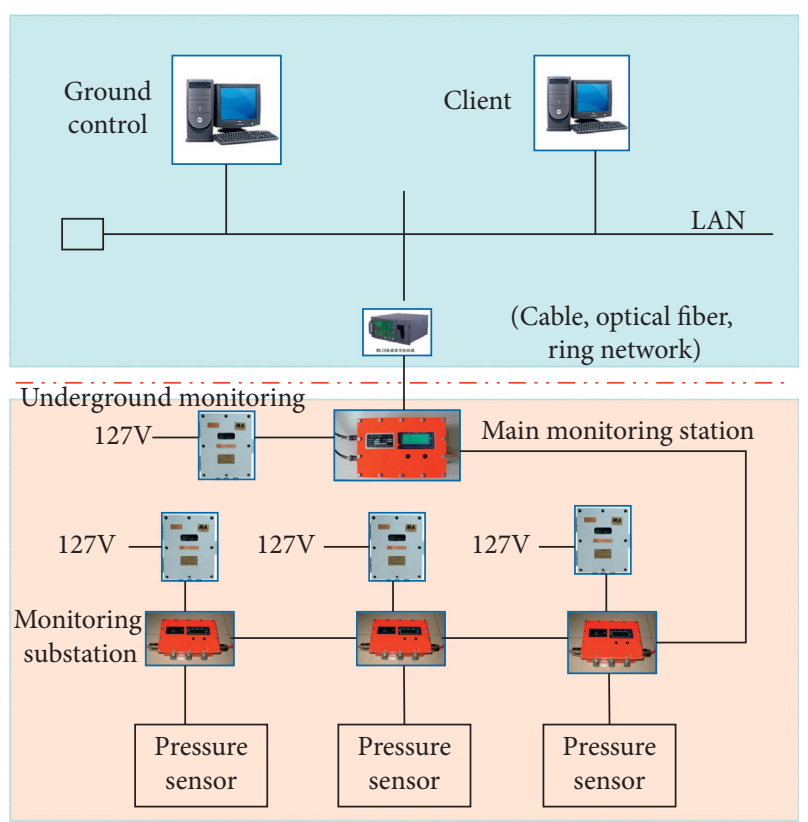

FIGURE 10: Monitoring system composition.

be measured is larger, the supporting rod needs to be added. The simple way is to fix the metal tube on the floor to a certain height and install the position meter on the upper part of the metal tube to contact with the roof. The structure diagram of the roof subsidence monitoring instrument is shown in Figure 11.

4.2. Stress Monitoring of Filling Body. The load on the filling body can directly act on the pressure sensor. The sensor is horizontally placed on the stope floor. When the floor is irregular, the sensor can be fixed to the steel plate and then placed on the bottom plate, as shown in Figure 12.

The structure of the pressure sensor is shown in Figure 13. The pressure of the filling medium directly acts on the strain of the sensor, which makes the strain produce elastic deformation. The strain gauge outputs a voltage signal proportional to the force applied, and the transmitter amplifies the voltage signal and outputs it.

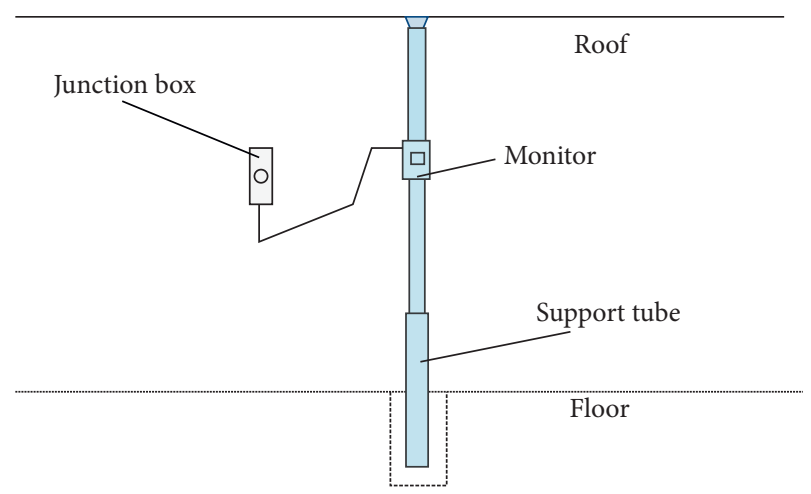

FIGURE 11: Supporting structure of top and bottom plate sinking position state instrument.

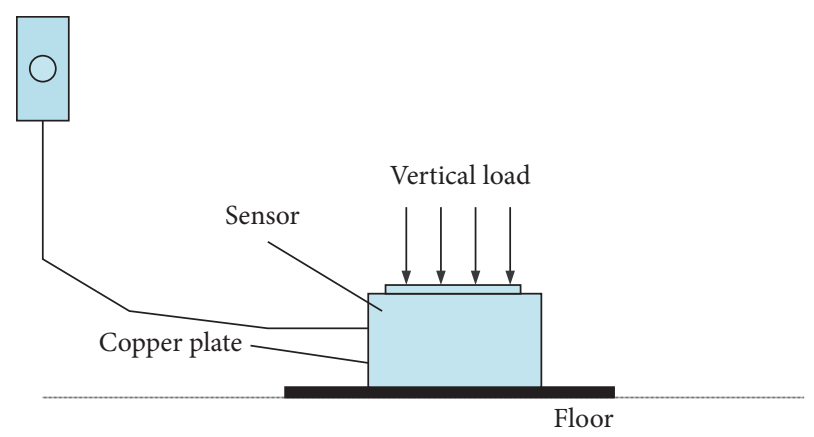

FIGURE 12: Layout of force monitoring sensor for filling body.

4.3. Monitoring Scheme. Four survey lines are set up in the stope. The first measuring line was arranged $138.7 \mathrm{~m}$ away from the filling cut of the working face. Due to the unclear understanding of the field temperature and equipment, the equipment failed about 8 hours after filling. The second measuring line is installed at $158.1 \mathrm{~m}$ of the total advance of the working face, in which $011 \mathrm{Y}$ \# pressure sensor fails at the beginning of installation, and other equipment operates normally. The third measuring line is installed at $212.3 \mathrm{~m}$ of the working face, and the equipment operates normally. The fourth measuring line is installed at 456 meters ahead of the working face. The location and layout of each measuring line 


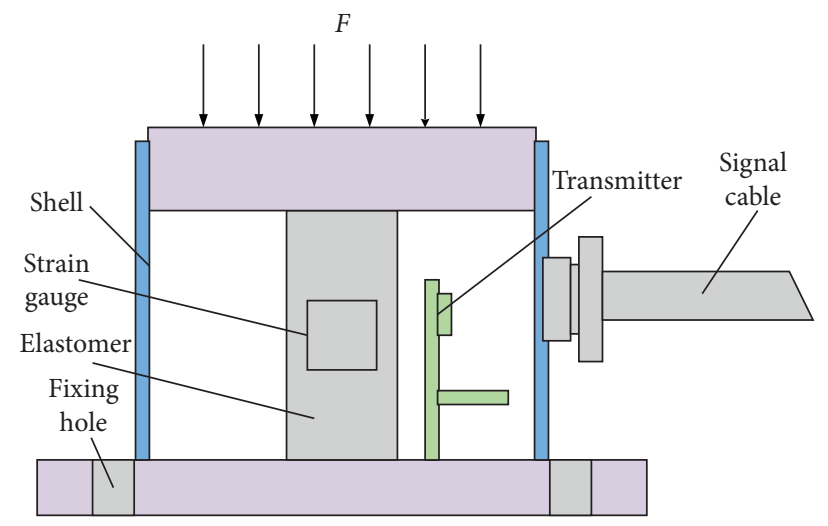

FIGURE 13: Structure of pressure sensor.

are shown in Figure 14, and the actual installation process is shown in Figure 15.

4.4. Monitoring Results and Analysis. Due to the high temperature of the water injection box, the connection box may be damaged due to the high temperature.

The following can be seen from the monitoring data Table 5:

(1) The maximum compression amount of the filling body occurs in the middle of the filling body, which is $104.4 \mathrm{~mm}$. The maximum compression amount at both ends of the filling body is only $52.7 \mathrm{~mm}$, and the maximum compression rate is $1.5 \sim 3.2 \%$ (the thickness of coal seam is $3.1 \mathrm{~m}$ ). The maximum pressure on the filling body also occurs in the middle of the filling body, which is $5.2 \mathrm{MPa}$, and the maximum pressure on both ends is only $3.8 \mathrm{MPa}$. It can be seen that the stress in the middle of the filling body is obviously greater than that at both ends, and the compression in the middle of the filling body is the largest.

The author thinks that this is mainly due to the fact that the roof in the middle of the filling body completely collapses on its upper part under pressure, and the weight of the roof and overlying strata is completely applied to the filling body, while the roof at both ends of the filling body plays a supporting role for the two ends of the roof due to the role of surrounding rock at both ends, and part of the top plate is in the "hanging" state due to the support; that is, a part of the weight is transferred to the surrounding rock All applied to the filling body. Therefore, in the later filling process, the strength of the middle part of the filling body should be increased as much as possible, and the strength at both ends of the filling body can be appropriately reduced. If the partition type filling technology is adopted and a different filling material ratio is adopted for different areas, the better filling effect can be achieved, the movement of the roof and overlying strata can be well controlled, the surface deformation can be limited, and the filling can be reduced. The cost of materials has achieved good economic benefits.

(2) The maximum pressure on the top of the filling body is $5.2 \mathrm{MPa}$, the maximum pressure at the bottom is 3.7 $\mathrm{MPa}$, and the difference is $1.5 \mathrm{MPa}$, which is about $30 \%$ of the maximum pressure on the top of the filling body. It can be seen that the stress on the top of the filling body is obviously greater than that on the bottom. It shows that the rock-like filling has a good function of absorbing and transferring stress and can absorb and transfer about $30 \%$ of the pressure when the roof is pressed. It also verifies that the filling proposed in [7] has good plastic strengthening characteristics, and it needs to absorb and consume more energy when it is damaged, so as to overcome the plastic deformation. This kind of performance of the filling body plays a good supporting role on the roof and reduces the risk of damage to the floor by the filling body.

\section{Discussions}

(1) Generally speaking, with the advance of working face, the stress of filling body increases gradually. When the working face is advanced about $40 \mathrm{~m}$, the stress of filling body increases linearly with the advance of working face. With the continuous advance of working face, the increasing range of stress gradually decreases, and the roof is basically stable. What is more noteworthy is that during the advancing process of the whole working face, there is no sudden change of stress on the filling body. This is mainly because the filling body gradually forms a common support system with the surrounding rock after compression deformation, which prevents the further subsidence of the roof rock and makes the roof rock gradually tend to be stable. Therefore, the stress of the filling body is also a gradually increasing and gradually stable process.

(2) The reading of the pressure box at the roof of the goaf is greater than that of the bottom, that is, the pressure on the top of the filling paste is obviously greater than that on the bottom, and the difference is about 


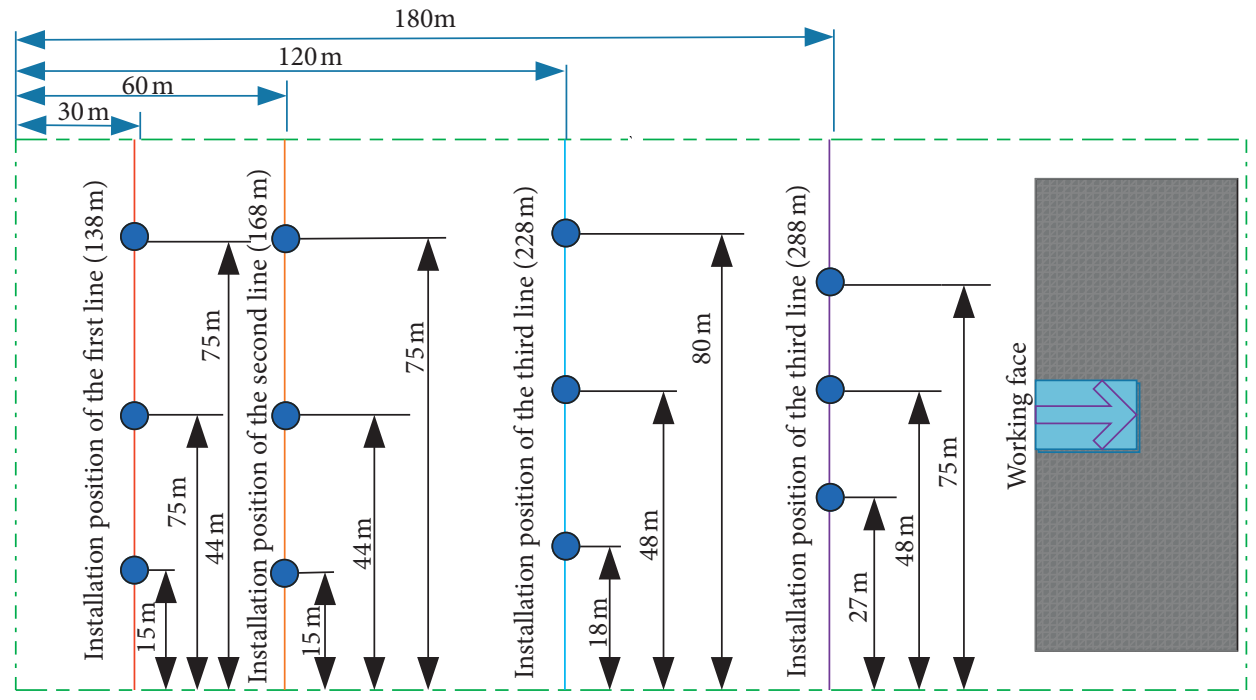

FIGURE 14: Equipment layout of 2351 rock-like filling face.

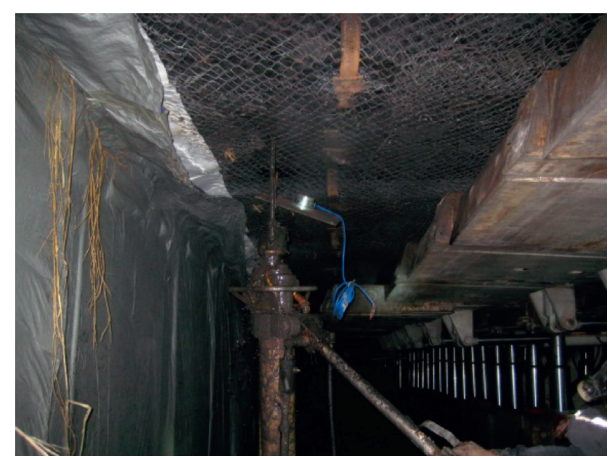

Figure 15: Installation of the roof pressure sensor.

TABle 5: Monitoring data of maximum stress and deformation of gangue filling body.

\begin{tabular}{|c|c|c|c|c|c|}
\hline Line number & $\begin{array}{c}\text { Number of pressure gauge } \\
\text { measuring points }\end{array}$ & $\begin{array}{l}\text { Maximum pressure of } \\
\text { measuring point }(\mathrm{MPa})\end{array}$ & $\begin{array}{c}\text { Number of pressure gauge } \\
\text { measuring points }\end{array}$ & $\begin{array}{l}\text { Maximum pressure of } \\
\text { measuring point }(\mathrm{MPa})\end{array}$ & $\begin{array}{c}\text { Position of } \\
\text { working face }\end{array}$ \\
\hline \multirow{2}{*}{ Line 1} & $11 \mathrm{Y}$ bottom & 1.3 & $11 \mathrm{~L}$ & -- & Top \\
\hline & $12 \mathrm{Y}$ bottom & 1.7 & $12 \mathrm{~L}$ & -- & Middle \\
\hline \multirow{2}{*}{ Line 2} & $21 Y$ bottom & 1.8 & $21 \mathrm{~L}$ & 35.3 & Top \\
\hline & $22 \mathrm{Y}$ bottom & 3.3 & $22 \mathrm{~L}$ & 54.6 & Middle \\
\hline \multirow{3}{*}{ Line 3} & $31 \mathrm{Y}$ bottom & 2.7 & $31 \mathrm{~L}$ & 52.7 & Top \\
\hline & $32 \mathrm{Y}$ top & 5.2 & $32 \mathrm{~L}$ & 104.4 & Middle \\
\hline & $33 \mathrm{Y}$ top & 3.8 & $33 \mathrm{~L}$ & 49.5 & Bottom \\
\hline \multirow{4}{*}{ Line 4} & $41 Y$ top & 3.5 & $41 \mathrm{~L}$ & 51.3 & Top \\
\hline & $42 \mathrm{Y}$ top & 5.1 & $42 \mathrm{~L}$ & 99.1 & Middle \\
\hline & $41 Y$ bottom & 2.2 & $43 \mathrm{~L}$ & 41.2 & Top \\
\hline & $42 \mathrm{Y}$ bottom & 3.7 & - & - & Middle \\
\hline
\end{tabular}

$2 \sim 2.5 \mathrm{MPa}$, which is about $1 / 4 \sim 1 / 2$ of the maximum pressure on the roof of the filling body. This shows that the rock-like filling body has a good function of absorbing and transferring stress and can absorb and transfer the stress. At the same time, it further verifies that the rock-like filling has good plastic strengthening characteristics, and it needs to absorb and consume more energy to overcome the plastic deformation. This kind of performance of the filling body plays a good supporting role on the roof and reduces the risk of damage to the floor by filling body. 


\section{Conclusions}

(1) Through the hierarchical fuzzy decision-making method, it can be seen that the optimal proportion scheme of gangue gypsum filling material is "E3," that is, the cement content is $9 \%$, the ratio of cement to gangue is $2: 5$, and the mass concentration is $74 \%$. The fuzzy decision-making results are consistent with the results of the orthogonal test. At the same time, the data show that the sensitivity degree of "ash to gangue ratio" in the optimization of gangue gypsum filling material proportion is the highest, followed by "cement content" and "mass concentration." Therefore, in the design of gangue gypsum filling material proportion, we should pay special attention to the "ash to gangue ratio" parameter and strictly control the amount of fly ash in the actual production.

(2) AHP and the fuzzy decision-making method are used to optimize the proportion of filling materials, and the fuzzy and complex problems are mathematically and systematically combined with qualitative and quantitative methods. The mathematical model of filling material ratio optimization is constructed, which not only avoids the error of the traditional filling material test but also overcomes the disadvantage of a large amount of data of the traditional mathematical statistics method. At the same time, combined with expert experience and opinions, the optimization result is scientific, reasonable, and consistent with the actual situation, which provides a new decision-making method for the selection of filling material proportion optimization scheme.

(3) The mass concentration is the main factor affecting the slump of slurry, and the specific gravity of fly ash and gangue directly affects the stratification and bleeding rate of slurry. The fluidity of the slurry can be improved by properly reducing the mass concentration of the slurry; the workability and water retention of the slurry can be significantly improved by reasonably increasing the ash gangue ratio, that is, the amount of fine aggregate in the slurry, and the stratification and bleeding rate of the slurry can be reduced. The amount of composite cementitious materials is the main factor affecting the setting time of grouting materials and the strength of filling paste. Adding a small amount of desulfurized gypsum into cement clinker can promote the hydration reaction of cement clinker, shorten the setting time of slurry, and improve the strength of the filling body.

(4) It is found that the compressive strength, tensile strength, and maximum elastic modulus of backfill increase gradually with the increase of age, while Poisson's ratio first increases and then decreases with the increase of age, and the mechanical parameters tend to be stable after 28 days of age. The $28 \mathrm{~d}$ compressive strength is $5.89 \mathrm{MPa}$, the tensile strength is $1.17 \mathrm{MPa}$, the elastic modulus is 842.45 $\mathrm{MPa}$, and the maximum Poisson's ratio is 0.0698 .

(5) It is found that the stress in the middle of the filling body is greater than that at both ends, and the stress on the top is greater than that on the bottom. The maximum compression of the filling body is $104.4 \mathrm{~mm}$, and the maximum compression ratio is $1.5 \sim 3.2 \%$. The maximum pressure on the filling body is $5.2 \mathrm{MPa}$, which is less than the filling body strength of 5.3 $\mathrm{MPa}$ under the optimal ratio in 3.3 above and the measured compressive strength of the filling body measured on site is $5.89 \mathrm{MPa}$, which verifies that the optimization scheme of rock-like filling material performance is feasible and the long-term stability of the filling body in goaf is good.

\section{Data Availability}

The data used in this study are available from the corresponding author upon request.

\section{Conflicts of Interest}

The authors declare that they have no conflicts of interest.

\section{Acknowledgments}

This study was partially funded by the National Natural Science Foundation of China (Grant no. 51804178), Shandong Provincial Natural Science Foundation (ZR2020QE125), and 2020 Shandong Province Key R\&D Program [Soft Science Project] (ZR 2020RKB01083 and 2020RKB01167).

\section{References}

[1] J. X. Hao, Y. N. Wei, K. Yang et al., "Anisotropy of crack initiation strength and damage strength of coal reservoirs," Petroleum Exploration and Development, vol. 48, no. 1, pp. 1-12, 2021.

[2] J. Zhang, Q. Zhang, A. J. S. Spearing, X. Miao, S. Guo, and Q. Sun, "Green coal mining technique integrating miningdressing-gas draining-backfilling-mining," International Journal of Mining Science and Technology, vol. 27, no. 1, pp. 17-27, 2017.

[3] W. Guo, Y. Li, D. Yin, S. Zhang, and X. Sun, "Mechanisms of rock burst in hard and thick upper strata and rock-burst controlling technology," Arabian Journal of Geosciences, vol. 9, no. 10, pp. 1-11, 2016.

[4] X. Hao, L. Yuan, Y. Li et al., "Lateral deformation characteristics of coal with bump tendency based on uniaxial compression experiment," Journal of China University of Mining and Technology, vol. 47, no. 1, pp. 130-136, 2018.

[5] J. Li, Y. Huang, M. Qiao et al., "Effects of water soaked height on the deformation and crushing characteristics of loose gangue backfill material in solid backfill coal mining," Processes, vol. 6, no. 6, p. 64, 2018.

[6] J.-w. Zhang, H.-l. Wang, and S.-j. Chen, "Bearing capacity of backfill body and roof stability during strip coal pillar 
extracted with paste backfill," Geotechnical and Geological Engineering, vol. 36, no. 1, pp. 235-245, 2018.

[7] M. G. Qian, J. L. Xu, and X. X. Miao, "Green technique in coal," Journal of China University of Mining \& Technology, vol. 32, no. 4, pp. 343-348, 2003, in Chinese.

[8] M. Y. Mu, X. M. Hu, Q. Zhang et al., "Orthogonal experimental studies on preparation of mine-filling materials from carbide slag, granulated blast-furnace slag, fly ash, and fluegas desulphurisation gypsum," Advances in Materials Science and Engineering, vol. 2018, pp. 11-23, 2018.

[9] L. J. Gardner, S. A. Bernal, S. A. Walling, C. L. Corkhill, J. L. Provis, and N. C. Hyatt, "Characterisation of magnesium potassium phosphate cements blended with fly ash and ground granulated blast furnace slag," Cement and Concrete Research, vol. 74, pp. 78-87, 2015.

[10] H. Du, L. Yang, W. Gao, and J. Liu, "Effects of characteristics of fly ash on the properties of geopolymer," Transactions of Tianjin University, vol. 22, no. 3, pp. 261-267, 2016.

[11] M. Fall, J. C. Célestin, M. Pokharel, and M. Touré, "A contribution to understanding the effects of curing temperature on the mechanical properties of mine cemented tailings backfill," Engineering Geology, vol. 114, no. 3-4, pp. 397-413, 2010.

[12] C. Hao, M. Deng, L. Mo, and K. Liu, "Surface modification of fly ashes with carbide slag and its effect on compressive strength and autogenous shrinkage of blended cement pastes," Journal of Wuhan University of Technology-Mater. Sci. Ed.vol. 27, no. 6, pp. 1149-1153, 2012.

[13] G. Zhou, Q. Zhang, R. Bai, T. Fan, and G. Wang, "The diffusion behavior law of respirable dust at fully mechanized caving face in coal mine: CFD numerical simulation and engineering application," Process Safety and Environmental Protection, vol. 106, pp. 117-128, 2017.

[14] Q. Liu, W. Nie, Y. Hua, H. Peng, and Z. Liu, "The effects of the installation position of a multi-radial swirling air-curtain generator on dust diffusion and pollution rules in a fullymechanized excavation face: a case study," Powder Technology, vol. 329, pp. 371-385, 2018.

[15] X. Zhang, W. Liu, X. Sun et al., "Research and practice on shortwall part filling technology using fly ash high-water material," Journal of China Coal Society, vol. 41, no. 12, pp. 3016-3023, 2016, in Chinese.

[16] M. A. Sobhi, L. Li, and M. Aubertin, "Numerical investigation of earth pressure coefficient along central line of backfilled stopes," Canadian Geotechnical Journal, vol. 54, no. 1, pp. 138-145, 2017.

[17] X. Zhang, J. Lin, J. Liu, F. Li, and Z. Pang, "Investigation of hydraulic-mechanical properties of paste backfill containing coal gangue-fly ash and its application in an underground coal mine," Energies, vol. 10, no. 9, p. 1309, 2017.

[18] F. Macías, C. R. Cánovas, P. Cruz-Hernández et al., “An anomalous metal-rich phosphogypsum: characterization and classification according to international regulations," Journal of Hazardous Materials, vol. 331, pp. 99-108, 2017.

[19] L. R. de Rezende, T. d. S. Curado, M. V. Silva et al., "Laboratory study of phosphogypsum, stabilizers, and tropical soil mixtures," Journal of Materials in Civil Engineering, vol. 29, no. 1, 2017.

[20] L. Dong, W. Shu, X. Li, Z. Zhou, F. Gong, and X. L. Liu, "Quantitative evaluation and case study of risk degree for underground goafs with multiple indexes considering uncertain factors in mines," Geofluids, vol. 2017, Article ID 3271246, 15 pages, 2017.

[21] M. Wang, X. Shi, J. Zhou, and X. Qiu, "Multi-planar detection optimization algorithm for the interval charging structure of large-diameter longhole blasting design based on rock fragmentation aspects," Engineering Optimization, vol. 50, no. 12, pp. 2177-2191, 2018.

[22] L. Dong, W. Shu, X. Li, and J. Zhang, "Quantitative evaluation and case studies of cleaner mining with multiple indexes considering uncertainty factors for phosphorus mines," Journal of Cleaner Production, vol. 183, pp. 319-334, 2018.

[23] W. Sun, K. Hou, Z. Yang, and Y. Wen, "X-ray CT three-dimensional reconstruction and discrete element analysis of the cement paste backfill pore structure under uniaxial compression," Construction and Building Materials, vol. 138, pp. 69-78, 2017.

[24] V. Favero, A. Ferrari, and L. Laloui, "Anisotropic behaviour of opalinus clay through consolidated and drained triaxial testing in saturated conditions," Rock Mechanics and Rock Engineering, vol. 51, no. 5, pp. 1305-1319, 2018.

[25] Q. Cheng, K. Yao, and Y. Liu, "Stress-dependent behavior of marine clay admixed with fly-ash-blended cement," International Journal of Pavement Research and Technology, vol. 11, no. 6, pp. 611-616, 2018.

[26] Y. Huang, J. Zhang, Q. Zhang, and S. Nie, "Backfilling technology of substituting waste and fly ash for coal underground in China coal mining area," Environmental Engineering and Management Journal, vol. 10, no. 6, pp. 769-775, 2011.

[27] J. M. Xu, J. X. Zhang, and Y. L. Huang, "Experimental research on the compress deformation characteristic of waste-flash and its application in backfilling fully mechanized coal mining technology," Journal of Mining \& Safety Engineering, vol. 28, no. 1, pp. 158-162, 2011.

[28] J. X. Wang and T. Q. Liu, "Feasibility study on the technology of filling the vacant space of the caving rock with cement materials," Coal Mining Technology, vol. 1, pp. 44-46, 2001.

[29] H. Yang, S. Cao, S. Wang, Y. Fan, S. Wang, and X. Chen, "Adaptation assessment of gob-side entry retaining based on geological factors," Engineering Geology, vol. 209, pp. 143-151, 2016.

[30] A. Wu, H. Li, H. Cheng, Y. Wang, C. Li, and Z. Ruan, "Status and prospects of researches on rheology of paste backfill using unclassified-tailings (part 1): concepts, characteristics and models," Chinese Journal of Engineering, vol. 208, pp. 138-152, 2020, In press.

[31] X. Hao, W. Du, Y. Zhao et al., "Dynamic tensile behaviour and crack propagation of coal under coupled static-dynamic loading," International Journal of Mining Science and Technology, vol. 30, no. 5, pp. 659-668, 2020.

[32] H. Cheng, S. Wu, H. Li, and X. Zhang, "Influence of time and temperature on rheology and flow performance of cemented paste backfill," Construction and Building Materials, vol. 231, Article ID 117117, 2020.

[33] N. Jiang, C. Wang, H. Pan, D. Yin, and J. Ma, "Modeling study on the influence of the strip filling mining sequence on mining-induced failure," Energy Science \& Engineering, vol. 8, no. 6, pp. 2239-2255, 2020.

[34] W. Piasta and B. Zarzycki, "The effect of cement paste volume and $\mathrm{w} / \mathrm{c}$ ratio on shrinkage strain, water absorption and compressive strength of high performance concrete," Construction and Building Materials, vol. 140, pp. 395-402, 2017.

[35] E. Yilmaz, T. Belem, B. Bussière, and M. Benzaazoua, "Relationships between microstructural properties and compressive strength of consolidated and unconsolidated cemented paste backfills," Cement and Concrete Composites, vol. 33, no. 6, pp. 702-715, 2011.

[36] W. P. Gonçalves, V. J. Silva, R. R. Menezes, G. A. Neves, H. L. Lira, and L. N. L. Santana, "Microstructural, physical and mechanical behavior of pastes containing clays and alumina waste," Applied Clay Science, vol. 137, pp. 259-265, 2017. 